\title{
Comparing the Relaxing Effects of Different Virtual Reality Environments in the Intensive Care Unit: Observational Study
}

Stephan M Gerber ${ }^{1}$, MSc; Marie-Madlen Jeitziner ${ }^{2}$, PhD; Simon D Sänger ${ }^{1}$, MSc; Samuel E J Knobel ${ }^{1}$, MSc; Laura Marchal-Crespo ${ }^{1}$, Prof Dr; René M Müri ${ }^{1,3}$, Prof Dr; Joerg C Schefold ${ }^{2}$, Prof Dr; Stephan M Jakob ${ }^{2}$, Prof Dr; Tobias $\mathrm{Nef}^{1,4}$, Prof Dr

${ }^{1}$ Gerontechnology \& Rehabilitation Group, University of Bern, Bern, Switzerland

${ }^{2}$ Department of Intensive Care Medicine, University Hospital Bern (Inselspital), University of Bern, Bern, Switzerland

${ }^{3}$ Department of Neurology, University Neurorehabilitation, University Hospital Bern (Inselspital), University of Bern, Bern, Switzerland

${ }^{4}$ ARTORG Center for Biomedical Engineering Research, University of Bern, Bern, Switzerland

\section{Corresponding Author:}

Tobias Nef, Prof Dr

Gerontechnology \& Rehabilitation Group

University of Bern

Murtenstrasse 50

Bern, 3008

Switzerland

Phone: 41316327579

Email: tobias.nef@artorg.unibe.ch

\section{Abstract}

Background: After a prolonged intensive care unit (ICU) stay, approximately 50\%-75\% of all critically ill patients suffer from neurocognitive late effects and a reduction of health-related quality of life. It is assumed that the noisy and stressful ICU environment leads to sensory overload and deprivation and potentially to long-term cognitive impairment.

Objective: In this study, we investigated three different virtual reality environments and their potentially restorative and relaxing effects for reducing sensory overload and deprivation in the ICU.

Methods: A total of 45 healthy subjects were exposed to three different environments, each 10 minutes in length (dynamic, virtual, natural, and urban environments presented inside the head-mounted display, and a neutral video on an ICU TV screen). During the study, data was collected by validated questionnaires (ie, restoration and sickness) and sensors to record physiological parameters (240 hertz).

Results: The results showed that the natural environment had the highest positive and restorative effect on the physiological and psychological state of healthy subjects, followed by the urban environment and the ICU TV screen.

Conclusions: Overall, virtual reality stimulation with head-mounted display using a dynamic, virtual and natural environment has the potential, if directly used in the ICU, to reduce sensory overload and deprivation in critically ill patients and thus to prevent neurocognitive late effects.

(JMIR Perioper Med 2019;2(2):e15579) doi: 10.2196/15579

\section{KEYWORDS}

virtual reality; critical illness; intensive care unit; neurocognitive late effects; nature; urban; stimulation

\section{Introduction}

Approximately $50 \%-75 \%$ of critically ill patients experiencing a prolonged intensive care unit (ICU) stay will suffer from neurocognitive late effects $[1,2]$. Neurocognitive late effects (eg, deficits in learning and memory, slowed information processing, attention, concentration, and executive function) of critically ill patients have been associated with a reduced ability to cope with everyday activities and a significant reduction in quality of life after discharge [2-5]. In addition to the medical condition of critically ill patients itself (eg, organ failure, delirium, and muscle weakness and atrophy), the stressful environment is also an important contributor to neurocognitive late effects [6,7]. ICU patients are exposed to high noise levels, 
artificial light, and isolation from their common environment, which leads to sensory overload and deprivation and potentially to long-term cognitive impairment [7-9]. There is evidence that the early introduction of an intervention in the ICU has the greatest impact on long-term outcome [1,10]. Current clinical practice in the ICU to reduce functional impairment includes early mobilization and physiotherapy, but there is less consensus about how to reduce or prevent neurocognitive late effects [11]

We propose using virtual reality (VR) technology with head-mounted display to comfort and reduce the stress of ICU patients. A state-of-the art, head-mounted display for the presentation of stereoscopic images and three-dimensional sounds (developed for the gaming industry) provides sensors for measuring head movements, which allows the user to look around in the virtual environment. Thus, wearing a head-mounted display enables patients to experience virtual environments with their visual and auditory senses while being highly immersed [12]. Since vision and hearing are completely controlled by the head-mounted display, patients do not notice anything from their surroundings, thus helping them avoid the noisy and stressful ICU environment. The virtual environment presented inside a head-mounted display is a computer-generated, visual, and auditory replication of a real (eg, a forest or city) or imaginary (eg, a futuristic city) environment. Virtual environments must be designed carefully to avoid negative side effects (eg, cybersickness, oculomotor problems) $[13,14]$. This leads us to the question of what virtual environment would comfort ICU patients the most.

In a previous study, we showed that VR exposure to a virtual environment that replicates beautiful nature scenes is feasible and potentially beneficial for critically ill patients. The stimulation had a strong relaxing effect without any adverse effects. Participants reported that the VR exposure was calming and that they were immersed in the virtual environment [15]. Our head-mounted display complied with hygiene requirements in the ICU, and patients could use the head-mounted displays while lying in bed. Based on these preliminary results, we believe that head-mounted displays can be used as an early rehabilitative intervention to provide cognitive stimulation with the goal of reducing neurocognitive late effects.

In the present study, we compare the relaxing effects of a virtual nature environment with a virtual urban environment, in combination with noise-cancelling headphones. As a control condition, we selected watching a movie about intuition on a TV screen with loudspeakers. This choice was made because in the ICU patients are often invited to watch TV. We hypothesize that the relaxing effects of the natural environment will be greater than the urban environment, and both greater than the control condition. This expectation is based on two theories that propose that restorative environments restore neurocognitive late effects (ie, attention), physiological and emotional functions, and have protective effects against environmental stressors. First, the stress recovery theory states that restorative environments enable us to relax and recover from stress and mental fatigue, as seen in markers of physiological stress [16]. Second, the attention restoration theory claims that restorative environments enable us to restore depleted resources of attention since effortless attention (ie, cognition) is forced [17-19]. Therefore, an effective restorative environment must be rich, harmonious, soft, fascinating, and give the feeling of being away [19]. Natural environments are especially suitable for restoring depleted attention resources in a structured and effortless way [20,21]. Additionally, restoration when viewing static nature images is faster and more complete compared to urban images, and there is evidence that being present in the restorative environment has comparable restorative effects to virtual environments presented in a head-mounted display [16,19,22].

In this study, to measure the restorative effect and thus the reaction to the stimulation, we used questionnaires about perceived restoration and sickness (ie, the Perceived Restoration Scale [PRS] and the Simulator Sickness Questionnaire [SSQ]) in combination with standard medical physiological measures (eg, heart rate, respiration rate, blood pressure) to measure implications on the parasympathetic nervous system.

\section{Methods}

\section{Participant Recruitment and Demographics}

The study was conducted following the current version of the Declaration of Helsinki. All subjects participating in the study were recruited through the University of Bern, and the study was approved by the Ethics Committee of the Canton of Bern, Switzerland (KEK-Nr. 2017-02195). All subjects signed written informed consent before inclusion. Furthermore, specific consent was obtained to publish identifying information and images in an online open-access publication. The main exclusion criteria were auditory and visual impairments and being below the age of 18 .

\section{Neurocognitive Stimulation}

The study was conducted in a one-bed cubicle in the ICU of the University Hospital Bern. To stimulate the subjects, either a head-mounted display (HTC Vive, High Tech Computer Corporation, Taoyuan, Taiwan) or a classical ICU TV screen (MediTec TV, Bewatec, Telgte, Germany) was used. The head-mounted-display had a resolution of $1080 \times 1200$ pixels per eye, a field of view of 110 degrees, and a refresh rate of 90 hertz $(\mathrm{Hz})$, whereas the ICU TV screen had an 11.5-inch display and an aspect ratio of $4: 3$.

Subjects were stimulated two times with the head-mounted display (ie, virtual nature and urban VR stimulation, Figure 1) and once with the gold standard (control condition), a classical ICU TV screen (movie), with each interaction lasting 10 minutes. The nature VR stimulation consisted of a large island surrounded by water, with green hill areas, beaches, forests, plantations, and several animals such as elephants, giraffes, dolphins, birds, and butterflies. The designed urban VR stimulation consisted of a busy downtown, followed by a more relaxed old town. Pedestrians, cars, birds, aircrafts, and a construction site were among the many objects that could be found in the environment. In both cases, subjects were walking on a predefined path. In the control condition, a neutral documentary movie about intuition was presented (ie, combination of nature and urban scenes). 
Physiological parameters (ie, noninvasive arterial blood pressure, heart rate, and respiratory rate) were monitored by the in-house monitor system of the University Hospital (Carescape Monitor B650, GE Healthcare, Little Chalfont, United Kingdom). Respiration and heartrate were measured at a frequency of $240 \mathrm{~Hz}$, whereas blood pressure was measured every second minute. To simulate a real ICU scenario, the physiological monitor system constantly produced alarm sounds (eg, simulated arrhythmia). In addition, a noise meter was set up next to the subject to monitor and guarantee the overall noise level in the room was above 50 decibels. The bed was tilted up so that the subjects were in an upright position. The system was approved by the University Hospital's medical-technical department, except for use in critically ill patients and subjects (ie, hygiene and medical eligibility approved). To evaluate the perceived restorativeness of each stimulation, the PRS-11[23] (measured by a seven-point scale from not at all to completely) and for discomfort the SSQ [24] (measured by a four-point scale, from none to severe) were used. Both score scales were normalized on a score scale between zero and one.

Figure 1. Left: VR urban environment; right: VR nature environment. VR: virtual reality.
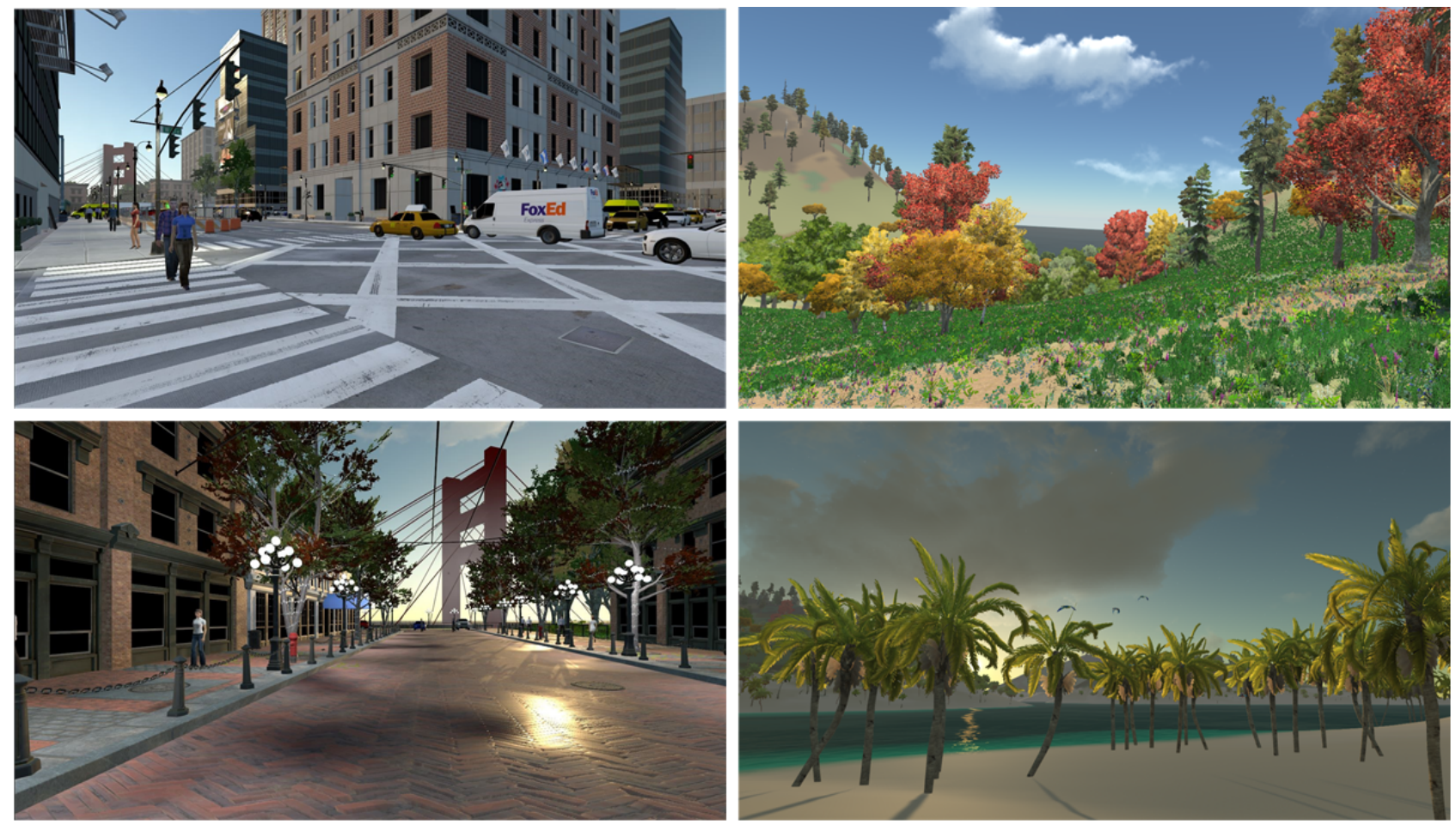

\section{Study Design and Procedure}

To account for the influence of the order of the stimulations, the subjects were randomly assigned in a pseudo cross-validation to one of the three groups with different stimulation sequences. First, subjects were instructed and prepared (ie, lying on the bed, Figure 2) for the experiment, followed by a recovery phase of 10 minutes to stabilize physiological parameters at subjects' baseline. Next, subjects were assigned randomly to one of the

three groups and stimulated with the three environments with a break of approximately 10 minutes in between. After each stimulation, they were asked to fill out a questionnaire of the perceived restorativeness and discomfort. Before the stimulation, subjects filled out a questionnaire about demographics. All instructions were given prior to the stimulation, and participants could move their head to explore the environment while seated. For each participant, the experiment lasted approximately 80 minutes. 
Figure 2. Subject during the stimulation in a VR environment, including the whole setup. ICU: intensive care unit; VR: virtual reality.

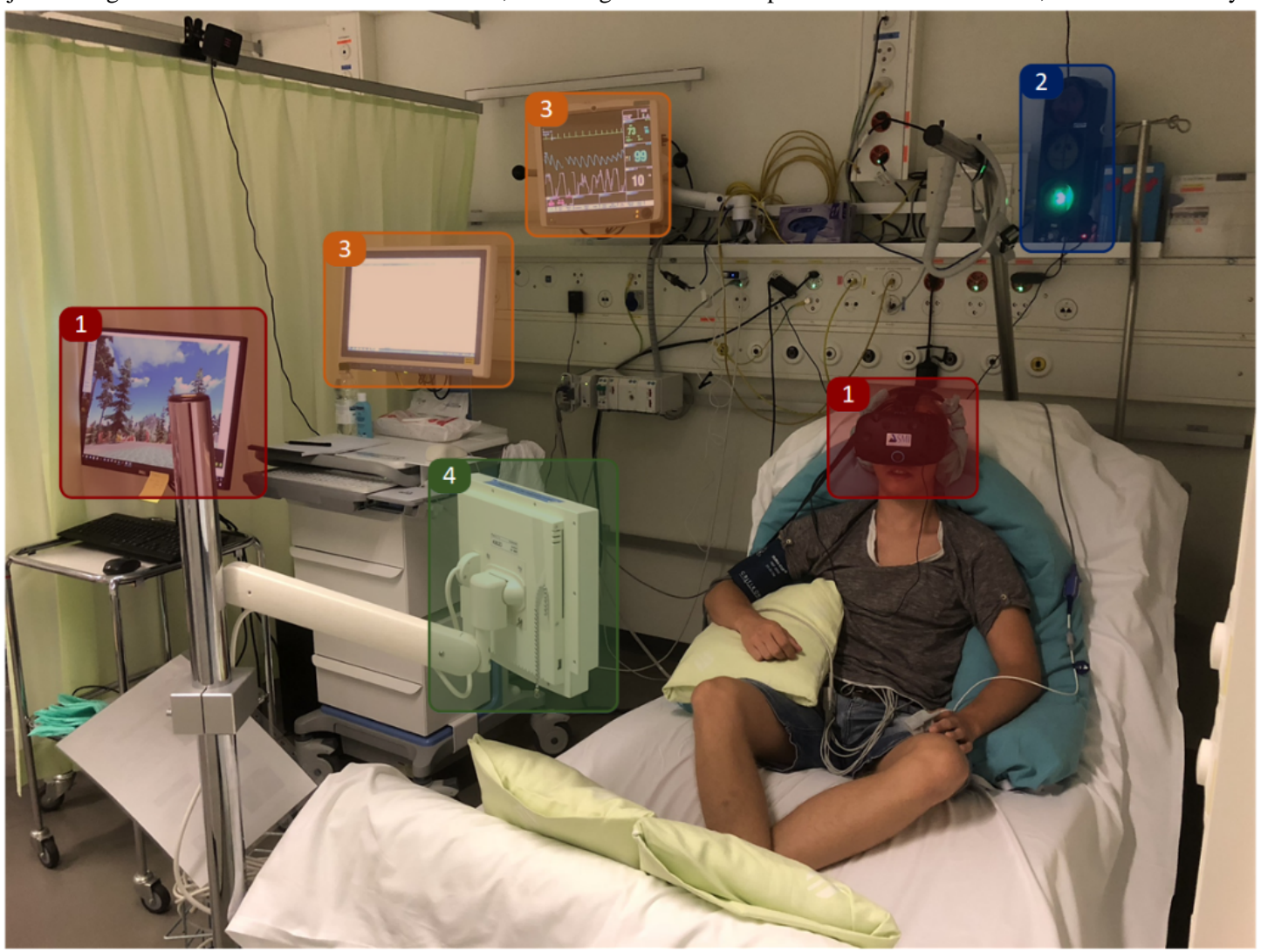

1 Head-mounted display, Noise-cancelling headphones \& Computer

2 Noise lamp

\section{Statistical Analysis}

To analyze the calming and relaxing effect (ie, negative time effect is defined as the reduction of physiological parameters during the course of the stimulation) of an environment, the correlation between time and the physiological measurement was calculated and tested on their significance using a one-tailed $t$ test against zero. To analyze the differences in questionnaire ratings between the stimulations, one-way analysis of variance (ANOVA) was used, followed by a post hoc analysis using paired $t$ tests and Bonferroni correction for $P$ value adjustment. The analysis of the physiological parameters and the questionnaires was conducted by using $\mathrm{R}$ for statistics (The $\mathrm{R}$ Foundation, Vienna, Austria) and MATLAB 2018b (MathWorks, Natick, USA).

\section{Website}

A video of the two VR stimulations and the movie about intuition can be found on our website [25].

\section{Data and Code Availability}

All relevant codes and data supporting the findings are presented in this paper. Further code and data of the study are available upon request.

\section{Results}

\section{Perceived Restoration}

A total of 45 (22 male and 23 female) adults between the ages of 22 and 87 (mean 59; SD 16) participated in the study. Overall, 29 participants grew up in the countryside and 16 in an urban environment, and they were all in good health. Analysis using ANOVA showed a significant difference between the three stimulation environments $\left(\mathrm{F}_{2}=15.86 ; P<.001\right)$. The nature VR stimulation had the highest perceived restoration (mean 0.773; SD 0.142) and was closest to the maximum of the score scale (with none=0 and high=1), followed by urban VR (mean 0.65715; SD 0.187) and ICU TV stimulation (mean 0.5854; SD 0.136). A post hoc analysis showed a significant difference between nature VR and both urban VR $(P=.002)$ and ICU TV $(P<.001)$, but not between urban VR and ICU TV stimulation $(P=.12)$.

In all three environments, nausea, oculomotor problems, and disorientation were close to the minimum of the score scale (Figure 3). The only significant difference in discomfort between the environments was found in disorientation $\left(\mathrm{F}_{2}=3.67 ; P=.03\right)$. 
Figure 3. The results of the Simulator Sickness Questionnaire for each of the three environments.

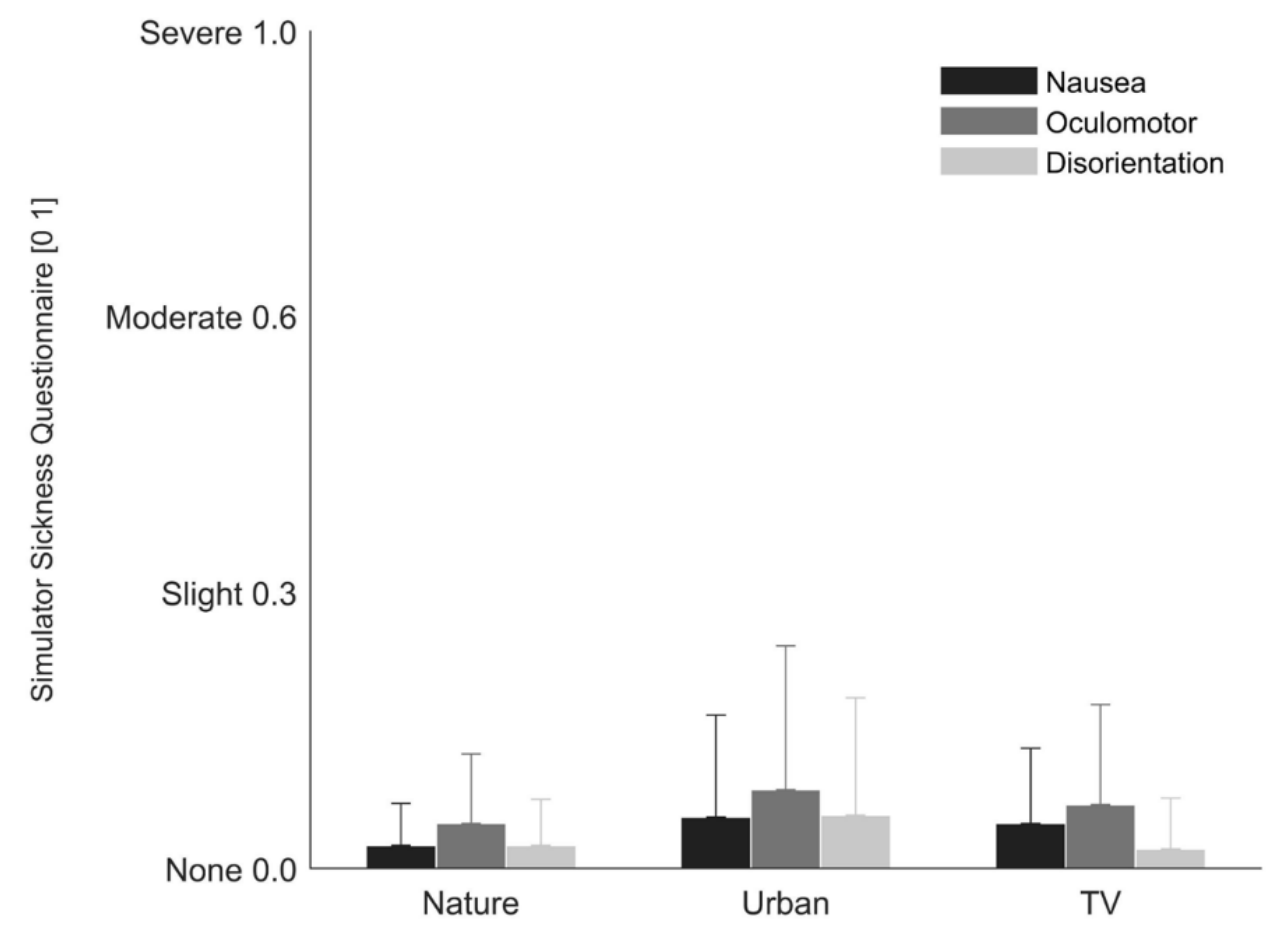

\section{Physiological Measurements}

At the beginning of the recovery phase, respiration rate was an average of 19.35 Breaths/minute (SD 5.08), heart rate was an average of 69.88 Beats/minute (SD 11.03), and the mean blood pressure was $94.3 \mathrm{mmHg}$ (SD 11.81). As shown in Figure 4, nature and urban VR stimulation were associated with a reduction in respiration rate, whereas during ICU TV stimulation respiration rate increased. The negative correlation of respiration rate and time (negative time effect) was highest and only significant in nature VR stimulation (95\% CI -Inf to -0.024; $\left.t_{42}=-2.13 ; P=.02\right)$, but neither in urban VR stimulation $(95 \%$
CI -Inf to $\left.0.052 ; t_{40}=-0.69 ; P=.25\right)$ nor in ICU TV stimulation (95\% CI - Inf to $\left.0.132 ; t_{41}=1.31 ; P=.90\right)$. With respect to heart rate, only nature VR decreased during the course of the stimulation, whereas in urban VR and ICU TV stimulation heart rate remained more or less constant. However, there was a significant negative time effect in heart rate in nature VR stimulation $\left(95 \% \mathrm{CI}-\mathrm{Inf}\right.$ to $\left.-0.177, t_{2}=-7.53 ; P<.001\right)$, in urban VR stimulation $\left(95 \% \mathrm{CI}-\right.$ Inf to $\left.0.161 ; t_{40}=-7.35 ; P<.001\right)$ and in ICU TV stimulation ( $95 \%$ CI -Inf to $\left.0.141 ; t_{38}=1.31 ; P<.001\right)$. Furthermore, the mean blood pressure did not increase or decrease during any of the three stimulations. 
Figure 4. Heart- and respiration rate of the three stimulation environments. In all cases, the standard deviation is shaded with the same color.
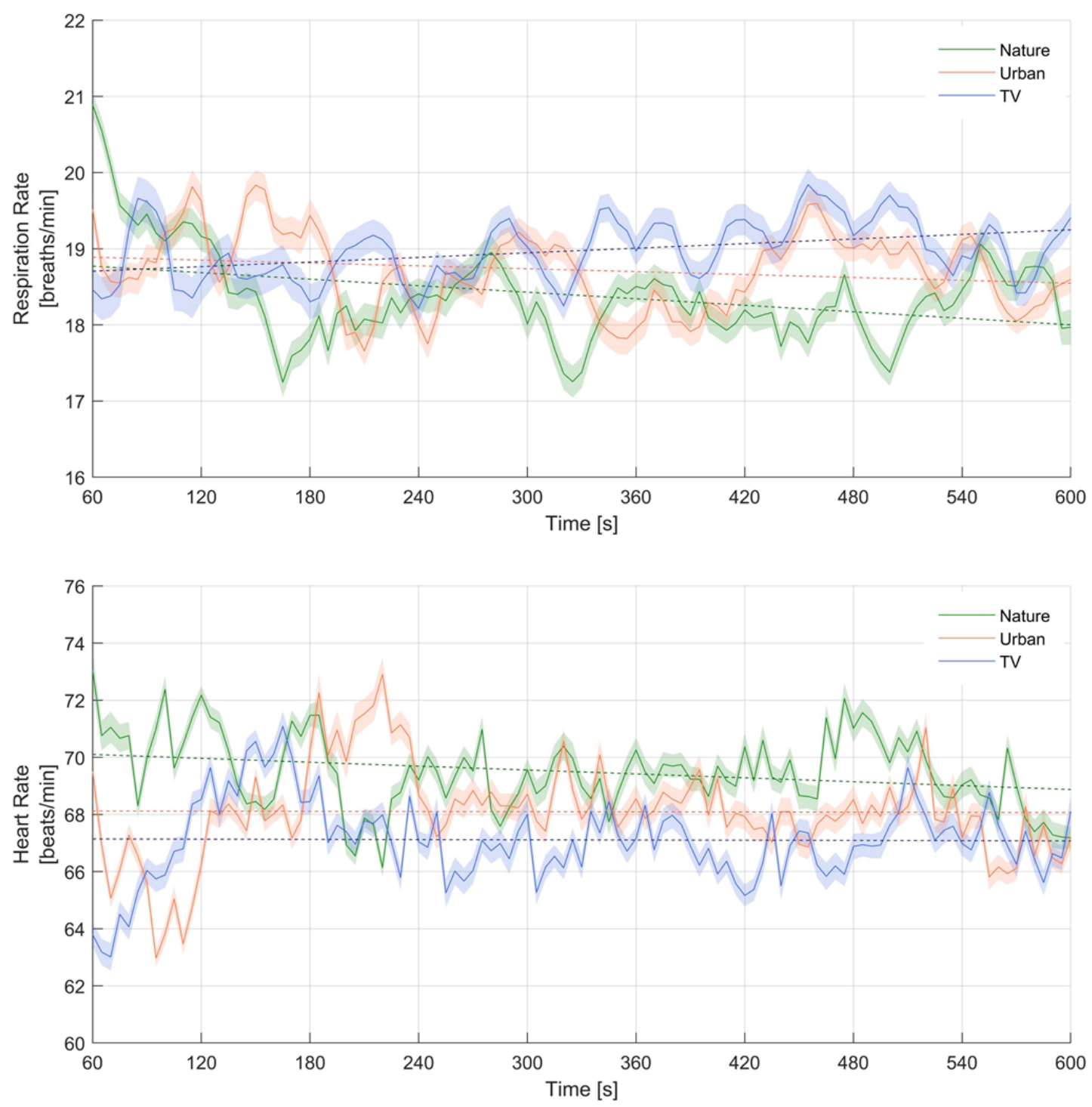

\section{Discussion}

\section{Primary Results}

In this study, we investigated the subjective restorative and relaxing effect of three different stimulation methods (dynamic, virtual, nature and urban environments presented inside a head-mounted display and a neutral video on an ICU TV screen) in healthy subjects. In line with our hypothesis, there was a significantly higher restorative and relaxing effect in the virtual nature environment compared to the virtual urban environment and the ICU TV screen. Additionally, in all cases, the three different methods evoked none to minor negative reactions.

\section{Perceived Restoration and Comfort}

The main finding in line with the attention restoration theory was that the highest perceived restorative effect was found in virtual nature stimulation, followed by the virtual urban stimulation and the movie presented on the ICU TV screen $[19,26]$. Furthermore, the three different stimulation methods showed none to minor negative side effects, like nausea, oculomotor problems, or disorientation. The slightly higher discomfort in the virtual urban environment was possibly due to unexpected 90 degree turns (ie, when walking around a building corner), whereas in the virtual nature environment no turns were present.

\section{Physiological Measurements}

The second main finding was that the nature VR stimulation with head-mounted display revealed the highest and only significant reduction in respiration rate. In case of heart rate, only the nature VR stimulation showed a relaxing effect, whereas in mean blood pressure no effect was found. Overall, physiological parameters showed that nature VR stimulation by using head-mounted displays revealed the greatest effect on the parasympathetic nervous system and thus was in line with the stress reduction theory suggestion that natural environments are the most restorative environment $[15,16,27]$.

The effect on the parasympathetic nervous system may not result just from the natural environment, but may also be influenced by the head-mounted display and the noise-cancelling headphones, which helped to reduce the sensory overload (eg, alarms, noise) and deprivation (eg, missing daylight) in the ICU. 
One may argue that this effect should also be present in the urban environment, but there is a significant difference between the stimuli of these environments. While the sound of the natural environment mostly consisted of crashing waves and animal sounds, the soundscape of the urban scene was overloaded with typical city sounds [28]. These sounds may be as irrelevant and annoying as the noises in the ICU and therefore also cause sensory overload. Furthermore, due to memories and past experiences in the different environments, not all participants will respond the same to the different stimuli. Therefore, if in the past participants had a bad experience with certain stimuli inside a natural (eg, animals) or an urban environment (eg, car accident) it may evoke bad memories and thus influence physiological parameters negatively, with the opposite being true for positive experiences.

\section{Limitations}

One of the limitations of this study is that all subjects were healthy subjects, so it is unclear whether the results could be transferred to critically ill patients. Another limitation was that cultural, living environment, and educational differences between the participants were recorded as a covariate but were not considered. Subjects from a rural origin may react differently to the stimulation and have different preferences than a subject who was born and grew up in a city. Furthermore, the different movement patterns inside the environments might have an influence on the perceived restorativeness.

\section{Conclusion}

Overall, three environments that were different in technical setup and design were tested safely and successfully. We showed that VR stimulation by using a head-mounted display in combination with a dynamic, virtual, natural environment had the highest restorative effect on the physiological and psychological state of a subject. Furthermore, it was shown that the effect was not simply due to the isolation from the stressful environment but actually due to the composition of the natural environment. Therefore, the method of VR nature stimulation by using a head-mounted display may have potential as an early-intervention method directly used in the ICU to reduce sensory overload and deprivation and thus prevent neurocognitive late effects.

\section{Acknowledgments}

The authors thank our clinical doctor and nursing team from the Department of Intensive Care Medicine at University Hospital Bern (Inselspital) for their commitment and helping to test the subjects. Furthermore, we would like to show our gratitude to all subjects who participated in the study. We are also immensely grateful to all co-workers at the Gerontechnology and Rehabilitation Research Group at University of Bern for ideas and support during the study. The study was funded by the University of Bern the Gerontechnology and Rehabilitation Research Group at ARTORG Center for biomedical engineering and the University Hospital Bern (Inselspital) Department of Intensive Care Medicine.

\section{Authors' Contributions}

SMG, MMJ, RMM, SMJ, and TN designed the study. SMG and SDS developed the setup and measured the participants together with MMJ. SMG, SDS, SEJK, and JCS analyzed the data. SMG, MMJ, SEJK, LM, RMM, JCS, SMJ, and TN wrote the manuscript. All authors approved the final manuscript. TN and SMJ share last authorship.

\section{Conflicts of Interest}

MMJ and JCS report grants from Orion Pharma, Abbott Nutrition International, B Braun Medical AG, CSEM AG, Edwards Lifesciences Services GmbH, Kenta Biotech Ltd, Maquet Critical Care AB, Omnicare Clinical Research AG, Nestle, Pierre Fabre Pharma AG, Pfizer, Bard Medica SA, Abbott AG, Anandic Medical Systems, Pan Gas AG Healthcare, Bracco, Hamilton Medical AG, Fresenius Kabi, Getinge Group Maquet AG, Dräger AG, Teleflex Medical GmbH, Glaxo Smith Kline, Merck Sharp and Dohme AG, Eli Lilly and Company, Baxter, Astellas, Astra Zeneca, CSL Behring, Novartis, Covidien, and Nycomed outside the submitted work. The money was paid into departmental funds, and there was no personal financial gain.

\section{References}

1. Wergin R, Modrykamien A. Cognitive impairment in ICU survivors: assessment and therapy. Cleve Clin J Med 2012 Oct;79(10):705-712. [doi: 10.3949/ccjm.79a.12038] [Medline: 23027729]

2. Wilcox ME, Brummel NE, Archer K, Ely EW, Jackson JC, Hopkins RO. Cognitive dysfunction in ICU patients: risk factors, predictors, and rehabilitation interventions. Crit Care Med 2013 Sep;41(9 Suppl 1):S81-S98. [doi: 10.1097/CCM.0b013e3182a16946] [Medline: 23989098]

3. Pandharipande PP, Girard TD, Jackson JC, Morandi A, Thompson JL, Pun BT, BRAIN-ICU Study Investigators. Long-term cognitive impairment after critical illness. N Engl J Med 2013 Oct 03;369(14):1306-1316 [FREE Full text] [doi: 10.1056/NEJMoa1301372] [Medline: 24088092]

4. Timmers TK, Verhofstad MHJ, Moons KGM, van Beeck EF, Leenen LPH. Long-term quality of life after surgical intensive care admission. Arch Surg 2011 Apr;146(4):412-418. [doi: 10.1001/archsurg.2010.279] [Medline: 21173281]

5. Hofhuis JGM, Spronk PE, van Stel HF, Schrijvers GJP, Rommes JH, Bakker J. The impact of critical illness on perceived health-related quality of life during ICU treatment, hospital stay, and after hospital discharge: a long-term follow-up study. Chest 2008 Feb;133(2):377-385. [doi: 10.1378/chest.07-1217] [Medline: 17925419] 
6. Lindenmuth JE, Breu CS, Malooley JA. Sensory Overload. The American Journal of Nursing 1980 Aug;80(8):1456. [doi: $10.2307 / 3462693$ ]

7. Leach J. Psychological factors in exceptional, extreme and torturous environments. Extrem Physiol Med 2016 Jun 1;5(1):7 [FREE Full text] [doi: 10.1186/s13728-016-0048-y] [Medline: 27257476]

8. Azouvi P, Vallat-Azouvi C, Belmont A. Cognitive deficits after traumatic coma. Progress in brain research 2009;177:89-110. [doi: 10.1016/s0079-6123(09)17708-7]

9. Brummel NE, Jackson JC, Girard TD, Pandharipande PP, Schiro E, Work B, et al. A combined early cognitive and physical rehabilitation program for people who are critically ill: the activity and cognitive therapy in the intensive care unit (ACT-ICU) trial. Phys Ther 2012 Dec 10;92(12):1580-1592 [FREE Full text] [doi: 10.2522/ptj.20110414] [Medline: 22577067]

10. Fuke R, Hifumi T, Kondo Y, Hatakeyama J, Takei T, Yamakawa K, et al. Early rehabilitation to prevent postintensive care syndrome in patients with critical illness: a systematic review and meta-analysis. BMJ Open 2018 May 05;8(5):e019998 [FREE Full text] [doi: 10.1136/bmjopen-2017-019998] [Medline: 29730622]

11. Brummel NE, Girard TD, Ely EW, Pandharipande PP, Morandi A, Hughes CG, et al. Feasibility and safety of early combined cognitive and physical therapy for critically ill medical and surgical patients: the Activity and Cognitive Therapy in ICU (ACT-ICU) trial. Intensive Care Med 2014 Mar;40(3):370-379 [FREE Full text] [doi: 10.1007/s00134-013-3136-0] [Medline: 24257969]

12. Székely G, Satava RM. Virtual reality in medicine. Interview by Judy Jones. BMJ 1999 Nov 13;319(7220):1305-1305 [FREE Full text] [doi: 10.1136/bmj.319.7220.1305] [Medline: 10559057]

13. Jäger M, Gruber N, Müri R, Mosimann UP, Nef T. Manipulations to reduce simulator-related transient adverse health effects during simulated driving. Med Biol Eng Comput 2014 Jul 3;52(7):601-610. [doi: 10.1007/s11517-014-1162-x] [Medline: 24888755]

14. LaViola JJ. A discussion of cybersickness in virtual environments. SIGCHI Bull 2000 Jan 01;32(1):47-56. [doi: $10.1145 / 333329.333344]$

15. Gerber SM, Jeitziner M, Wyss P, Chesham A, Urwyler P, Müri RM, et al. Visuo-acoustic stimulation that helps you to relax: A virtual reality setup for patients in the intensive care unit. Sci Rep 2017 Oct 16;7(1):13228 [FREE Full text] [doi: 10.1038/s41598-017-13153-1] [Medline: 29038450]

16. Ulrich RS, Simons RF, Losito BD, Fiorito E, Miles MA, Zelson M. Stress recovery during exposure to natural and urban environments. Journal of Environmental Psychology 1991 Sep;11(3):201-230. [doi: 10.1016/s0272-4944(05)80184-7]

17. Ohly H, White MP, Wheeler BW, Bethel A, Ukoumunne OC, Nikolaou V, et al. Attention Restoration Theory: A systematic review of the attention restoration potential of exposure to natural environments. J Toxicol Environ Health B Crit Rev 2016 Sep 26;19(7):305-343. [doi: 10.1080/10937404.2016.1196155] [Medline: 27668460]

18. Kaplan S. The restorative benefits of nature: Toward an integrative framework. Journal of Environmental Psychology 1995 Sep;15(3):169-182. [doi: 10.1016/0272-4944(95)90001-2]

19. Berto R. The role of nature in coping with psycho-physiological stress: a literature review on restorativeness. Behav Sci (Basel) 2014 Oct 21;4(4):394-409 [FREE Full text] [doi: 10.3390/bs4040394] [Medline: 25431444]

20. Berman MG, Jonides J, Kaplan S. The cognitive benefits of interacting with nature. Psychol Sci 2008 Dec;19(12):1207-1212. [doi: 10.1111/j.1467-9280.2008.02225.x] [Medline: 19121124]

21. Gamble KR, Howard JH, Howard DV. Not just scenery: viewing nature pictures improves executive attention in older adults. Exp Aging Res 2014 Oct 16;40(5):513-530 [FREE Full text] [doi: 10.1080/0361073X.2014.956618] [Medline: 25321942]

22. Yu C, Lee H, Luo X. The effect of virtual reality forest and urban environments on physiological and psychological responses. Urban Forestry \& Urban Greening 2018 Oct;35:106-114. [doi: 10.1016/j.ufug.2018.08.013]

23. Pasini M, Berto R, Brondino M, Hall R, Ortner C. How to Measure the Restorative Quality of Environments: The PRS-11. Procedia - Social and Behavioral Sciences 2014 Dec;159:293-297. [doi: 10.1016/j.sbspro.2014.12.375]

24. Kennedy RS, Lane NE, Berbaum KS, Lilienthal MG. Simulator Sickness Questionnaire: An Enhanced Method for Quantifying Simulator Sickness. The International Journal of Aviation Psychology 1993 Jul;3(3):203-220. [doi:

10.1207/s15327108ijap0303 3]

25. Gerber S. Stimulation Videos. Bern: Artorg Center for Biomedical Engineering, University of Bern; 2017. URL: https:/ /www.artorg.unibe.ch/research/ger/research/

development of an adaptive virtual environment for closed loop control of cognitive processes in critically ill patients/ index eng.html [accessed 2019-10-07]

26. Van den Berg AE, Joye Y, Koole SL. Why viewing nature is more fascinating and restorative than viewing buildings: A closer look at perceived complexity. Urban Forestry \& Urban Greening 2016 Dec;20:397-401. [doi: 10.1016/j.ufug.2016.10.011]

27. Valtchanov D, Barton KR, Ellard C. Restorative effects of virtual nature settings. Cyberpsychol Behav Soc Netw 2010 Oct;13(5):503-512. [doi: 10.1089/cyber.2009.0308] [Medline: 20950174]

28. Alvarsson JJ, Wiens S, Nilsson ME. Stress recovery during exposure to nature sound and environmental noise. Int J Environ Res Public Health 2010 Mar 11;7(3):1036-1046 [FREE Full text] [doi: 10.3390/ijerph7031036] [Medline: 20617017] 


\section{Abbreviations}

ANOVA: analysis of variance

Hz: hertz

ICU: intensive care unit

Inf: infinity

PRS-11: Perceived Restorativeness Questionnaire

SSQ: Simulator Sickness Questionnaire

VR: virtual reality

Edited by G Eysenbach; submitted 22.07.19; peer-reviewed by J Choi, IN Gomez, J Zhou; comments to author 21.08.19; revised version received 08.09.19; accepted 23.09.19; published 15.11.19

Please cite as:

Gerber SM, Jeitziner MM, Sänger SD, Knobel SEJ, Marchal-Crespo L, Müri RM, Schefold JC, Jakob SM, Nef T

Comparing the Relaxing Effects of Different Virtual Reality Environments in the Intensive Care Unit: Observational Study

JMIR Perioper Med 2019;2(2):e15579

URL: http://periop.jmir.org/2019/2/e15579/

doi: $\underline{10.2196 / 15579}$

PMID: $\underline{33393906}$

CStephan M Gerber, Marie-Madlen Jeitziner, Simon D Sänger, Samuel E J Knobel, Laura Marchal-Crespo, René M Müri, Joerg C Schefold, Stephan M Jakob, Tobias Nef. Originally published in JMIR Perioperative Medicine (http://periop.jmir.org), 15.11.2019. This is an open-access article distributed under the terms of the Creative Commons Attribution License (https://creativecommons.org/licenses/by/4.0/), which permits unrestricted use, distribution, and reproduction in any medium, provided the original work, first published in JMIR Perioperative Medicine, is properly cited. The complete bibliographic information, a link to the original publication on http://periop.jmir.org, as well as this copyright and license information must be included. 